\title{
EFFECTS OF ENVIRONMENTAL XENOBIOTICS ON THE NERVOUS SYSTEM IN ANIMAL EXPERIMENTS
}

\author{
András PAPP - Tünde VEZÉR - Andrea SZABÓ - László NAGYMAJTÉNYI
}

Department of Public Health, University of Szeged Faculty of Medicine Szeged, Hungary

\section{Introduction}

Food is a major route by which xenobiotics - mostly produced and emitted by man - can cause human exposure. Pesticides are deliberately brought into the environment in huge amounts in order to eliminate, by toxic action, insects, fungi, weeds etc. endangering agricultural production; but, due to incomplete selectivity and/or persistence, can expose field workers and food consumers (Conway and Pretty, 1991; Faheed, 2005). Modern insecticides were designed to attack the nervous system of insects and other arthropods. Some of them, however, turned out to be persistent and ecotoxic (WHO, 1989a,b) while others (e.g., organophosphates: WHO, 1986) have a high acute human toxicity.

The use of heavy metals for centuries resulted in considerable levels of lead, mercury etc. in soil, water and sometimes food samples (ATSDR, 1999a,b; Jolánkai et al., 2006; Osztoics et al., 2005). The ill effects of heavy metals on the human nervous system, form peripheral nerves to behavioral and learning abnormalities, is well known.

Neurotoxicity, seems to be an important aspect of environmental xenobiotics. Functional or structural damage of the nervous system can compromise an individual's fitness for work and general quality of life. Neurotoxic influences during foetal and early postnatal development, an especially sensitive phase, can have lasting effect on the mental performance in the adulthood and so affect the most precious quality of human resources. At the Department of Public Health, University of Szeged Faculty of Medicine, the neurotoxicity of environmental xenobiotics has been investigated in animal experiments for ca. 20 years, applying electrophysiological and behavioral techniques. In this paper, examples of our results are given.

\section{Materials and Methods}

All experiments were done on rats of the Wistar strain. In the subacute/subchronic scheme, 10 weeks old male rats were exposed by the investigated substance orally (by gavage) for 5 to 12 weeks, 5 times a week. In the developmental scheme, pregnant females were treated daily from the $5^{\text {th }}$ to $15^{\text {th }}$ day of pregnancy ( $\mathrm{P}$ protocol); or were treated as above plus during lactation from the $2^{\text {nd }}$ day after delivery until weaning (pregnancy+lactation: $\mathrm{P}+\mathrm{L}$ protocol); or the male offspring after the $\mathrm{P}+\mathrm{L}$ protocol was treated for further 8 weeks in a 5 days per week schedule $(\mathrm{P}+\mathrm{L}+\mathrm{P}$ protocol).

For electrophysiological recording after the treatment period, the rats were anaesthetised with urethane, the skull was opened, and spontaneous electrical activity of the cortex (electrocorticogram, ECoG), and sensory evoked potentials (EPs) were recorded from the primary sensory areas by silver electrodes (in this paper, only records from the somatosensory area will be discussed). From the rats' tail, compound action potential of the tail nerve was recorded. In case of the ECoG, the frequency spectrum was determined 
(delta, theta etc. waves). The measured parameters of EPs were latency and duration. The calculated parameters of the tail nerve were conduction velocity and refractory period. In some experiments, behavioral tests were conducted during the treatment period. The spontaneous motor activity of the rats was investigated in an open field box, and their horizontal locomotion, rearing, and local motor activity (grooming etc.) was calculated automatically. The data were compared to untreated controls. Significance of the differences was tested by ANOVA. All investigations were performed in accordance with the principles of the Ethical Committee for the Protection of Animals in Research of our University. Some experiments were done under GLP-certified conditions (certification No: 3011/48/2003, issued by the Hungarian National Institute of Pharmacy).

\section{Results and Discussion}

Dimethoate (D) and amitraz (A) are two frequently used insecticides. After giving D $(20 \mathrm{mg} / \mathrm{kg}$ b.w.) and A (21 mg/kg b.w.) orally for 12 weeks, significant alterations were found in the functional parameters of the rats' somatosensory system (Fig. 1).
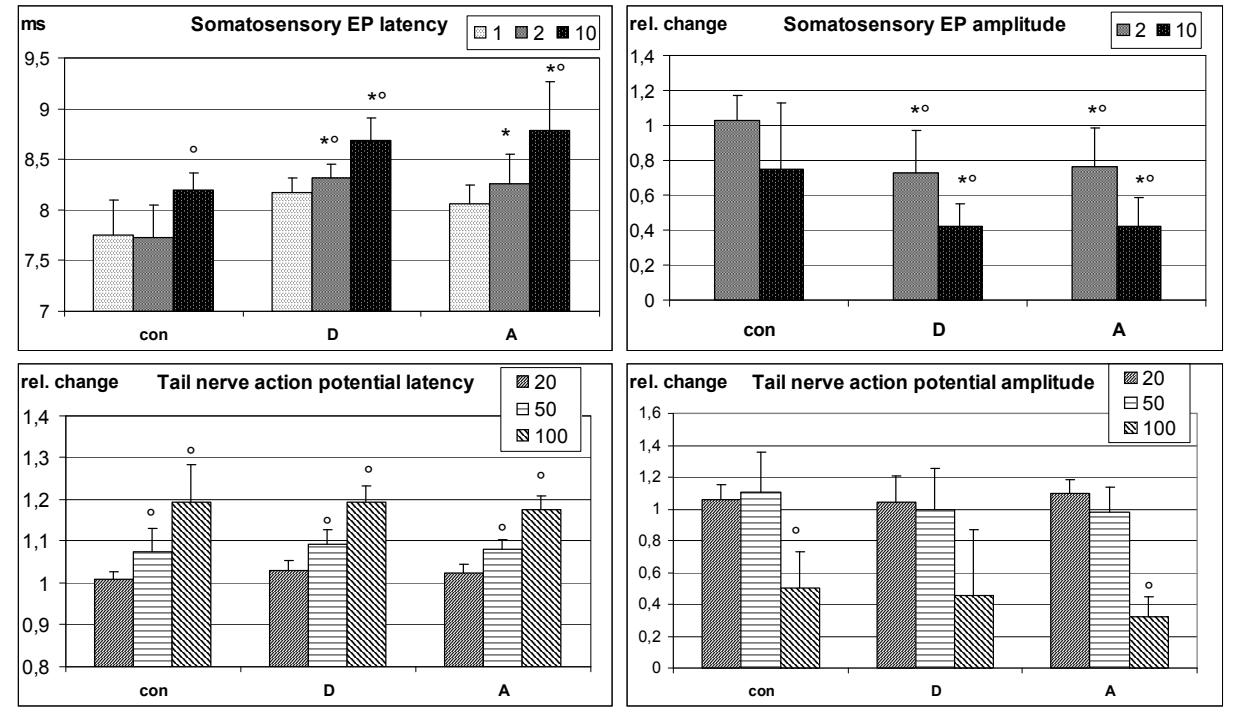

Figure 1. Parameters of the somatosensory cortical evoked potential and the tail nerve in rats treated with dimethoate (D) and amitraz (A). Relative change is defined vs. result with $1 \mathrm{~Hz}$ stimulation. Mean $+\mathrm{SD}, \mathrm{n}=10$. Insert: stimulation frequency $(\mathrm{Hz})$. $* \mathrm{p}<0.05$ vs. control ${ }^{\circ} \mathrm{p}<0.05$ vs. $1 \mathrm{~Hz}$ data within the group.

Latency and amplitude of the somatosensory EP increased significantly in both treated groups vs. control, and the change of this parameter on varying the frequency of stimulation was also altered. In spite of the different chemical character and mode of action, dimethoate and amitraz induced similar alterations. The reaction of the tail nerve evoked activity on the stimulation frequency was also sensitive to the presence of the insecticides.

Mercury is a well-known neurotoxic heavy metal, existing in the environment in various forms including methyl mercury. In the following experiment, methyl mercury 
$\left(\mathrm{CH}_{3} \mathrm{HgCl}\right)$ was administered to rats for 5 weeks, followed by a 12 -week post-treatment period. Before treatment, and at the end of the treatment and post-treatment periods, the spontaneous motor activity of the rats was tested. The open field results (Fig. 2) showed decreased motor activity which did not fully reverse during the 12 post-treatment weeks. The spectrum of the ECoG was not altered but the latency of the somatosensory EP increased significantly in the high dose group. The behavioral test sensitively indicated the effect of methyl mercury, which can be considered as a correlate of the well known higher order functional damages of humans with (e.g., alimentary) methyl mercury exposure.
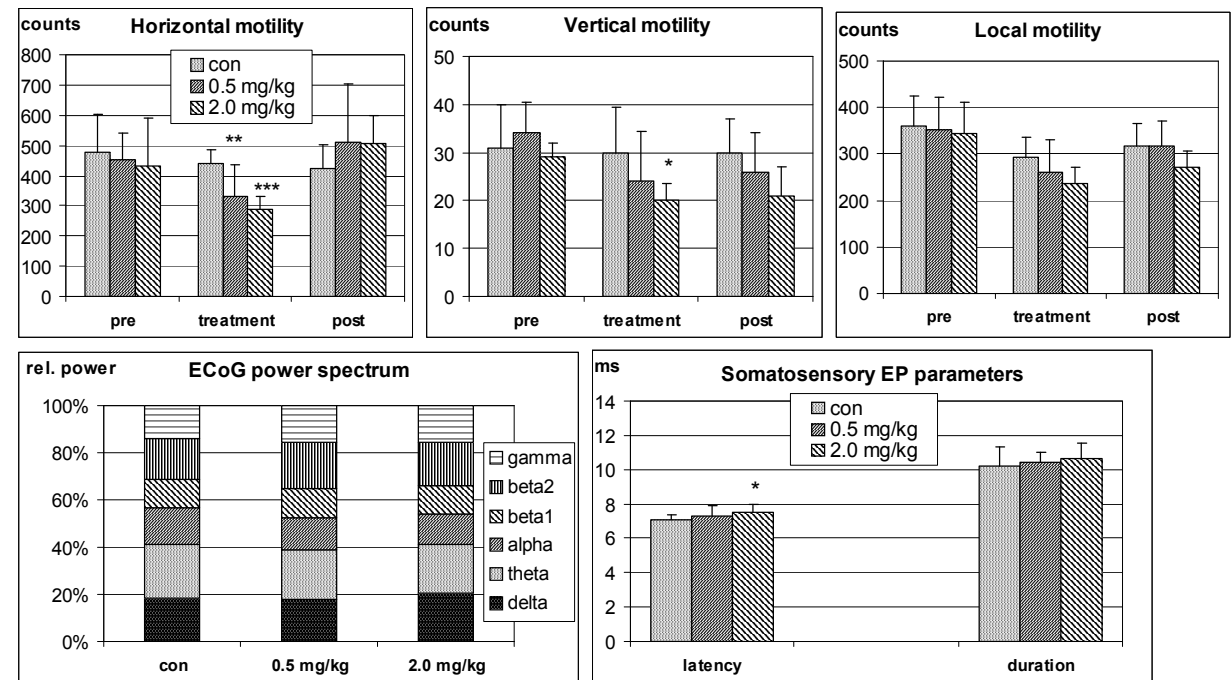

Figure 2. Results of spontaneous motor activity (upper row), and spontaneous and stimulus-evoked somatosensory cortical activity (lower row) of rats treated for 5 weeks with methyl mercury (doses: see insert). Bar graphs: mean $+\mathrm{SD}, \mathrm{n}=12$. $*, * *, * * * \mathrm{p}<0.05,0.01,0.001$ vs. control.

Real-life exposure is mostly mixed. In the next experiment, the insecticides dimethoate (D; $18.4 \mathrm{mg} / \mathrm{kg}$ b.w.), propoxur (P; $3.4 \mathrm{mg} / \mathrm{kg}$ ) and cypermethrin (C; $22.2 \mathrm{mg} / \mathrm{kg}$ ) were combined with lead $(320 \mathrm{mg} / \mathrm{kg})$ and mercury $(1.6 \mathrm{mg} / \mathrm{kg})$ as DPC and $\mathrm{PbHgD}$, and were given using the developmental scheme (see Methods). From the offspring, cortical activity was recorded in their 12 weeks of age.

The changes in the ECoG spectrum were partially opposite in pre vs. pre+postnatal treatment (Fig. 3). The shift to higher frequencies (typical for an organophosphate) was more marked if D was combined with the metals than if with other insecticides. The same was seen on the latency of the EP.

\section{Conclusions}

Our experiences showed that the effects of environmental xenobiotics on the nervous system can be modelled in animals. Animal experiments remain a major component of safety screening required e.g. by the new REACH system (EC, 2006). Some of the electrophysiological and behavioral tests presented here may have the potency of being 

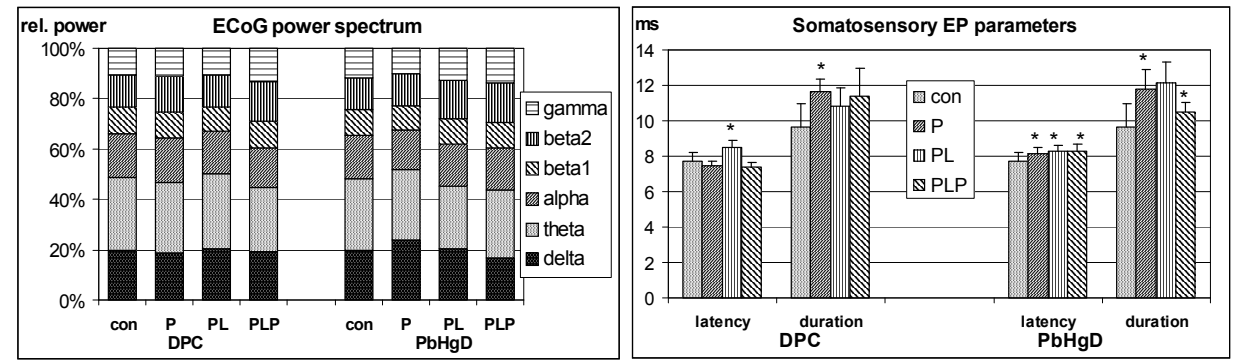

Figure 3. Spontaneous (left) and evoked (right) cortical activity after pre- and pre+postnatal exposure to triple combinations of environmental neurotoxicants (see text). Displayed as in Fig. 2

developed into human biomarkers of toxic effect. In the field of combined exposures and effects, further research is clearly needed (Beaumont and Buffin, 2002).

\section{Acknowledgements}

The work was supported by the Hungarian OTKA grant No. T 042955.

\section{References}

EC (2006) Regulation (EC) No. 1907/2006 of the European Parliament and of the Council. Offic. J. E.U. L396: 1-849.

Conway, G. - Pretty, J. (1991) Unwelcome Harvest: Agriculture and Pollution. Earthscan, London, pp. 32-81.

ATSDR (1999a) Toxicological Profile for Lead. US Department of Health and Human Services, Atlanta,.USA.

ATSDR (1999b) Toxicological Profile for Mercury. US Department of Health and Human Services, Atlanta,.USA.

WHO (1986) Organophosphorous Insecticides: a General Introduction. Environmental Health Criteria 63. WHO, Geneva.

WHO (1989a). Aldrin and Dieldrin. Environmental Health Criteria 91. WHO, Geneva. WHO (1989b) DDT and its Derivatives: Environmental Aspects. Environmental Health Criteria 83. WHO, Geneva.

Beaumont, P. - Buffin, D. (2002) A cocktail of problems. Pesticide News 55: 10-11. Faheed, F.A. (2005) Effect of lead stress on the growth and metabolism of Eruca sativa M. seedlings. Acta Agronomica Hungarica 53/3: 319 - 327.

Jolánkai, M. - Szentpétery, Zs., Hegedüs, Z. (2006) Pesticide residue dischange dynamics in wheat grain. Cereal Research Communications 34/1: 505-509.

Osztoics, E. - Csathó, P. - Radimszky, L. (2005) Az algériai nyersfoszfát és a szuperfoszfát hatásának vizsgálata $\mathrm{V}$. A talajtulajdonságok és a foszfortrágyák hatása tavaszi árpa (Hordeum vulgare) Cd-, Cr-, Co-, Ni-, Sr-, Mn-, Al- és Mo-koncentrációjára tenyészedény-kísérletben (Investigation of the effect of Algerian raw phosphate and superphosphate V. Effects of soil properties and phosphorus fertilizers on the Cd-, Cr-, $\mathrm{Co}-, \mathrm{Ni}-, \mathrm{Sr}-, \mathrm{Mn}-, \mathrm{Al}-$ and Mo content of barley (Hordeum vulgare) in vitro). Agrokémia és Talajtan 54/1-2: 105-120. 